\title{
Turismo cultural: análise bibliométrica e de redes sociais do campo de turismo no Brasil, 1990-2018
}

\author{
Andre Fontan Kohler* Luciano Antonio Digiampietri** \\ Universidade de São Paulo (Brasil)
}

\begin{abstract}
Resumo: Apresenta-se uma análise bibliométrica e de redes sociais do campo de turismo no Brasil, considerando-o como os artigos publicados em 16 periódicos brasileiros de turismo. Por meio das palavras-chave, é descrita e avaliada sua trajetória (1990-2018), com foco no agrupamento de turismo cultural. Acerca dele, abordam-se a autoria (autores, instituições e distribuição geográfica), periódicos (concentração da publicação), impacto e estrutura intelectual. O agrupamento é claramente delimitado, e congrega palavras-chave "esperadas," que orbitam em torno do turismo cultural, cultura e patrimônio. A autoria é relativamente fragmentada; há clara sobre representação da Região Nordeste do Brasil. Nas referências, chama atenção a orientação de ciências sociais; há relativamente poucos autores e textos preocupados com o turismo cultural como segmento de mercado. É nítido o domínio e centralidade de Margarita Barretto na estrutura intelectual. No impacto, o agrupamento tem uma média de citações reais por artigo pouco abaixo da verificada para o campo.
\end{abstract}

Palavras-chave: Turismo cultural; Bibliometria e análise de redes sociais; Autoria; Estrutura intelectual; Impacto.

Cultural tourism: bibliometric and social network analysis of Brazilian tourism field, 1990-2018

Abstract: We present a bibliometric and social network analysis of the Brazilian field of tourism, taken as the articles of 16 Brazilian tourism journals. Utilizing keywords, we describe and evaluate its trajectory (1990-2018), with focus on the cultural tourism cluster. We study the authorship (authors, institutions and geographic distribution), journals (dispersal of publication), impact and intellectual structure of the cluster. It is clearly delimited, and includes "expected" keywords that orbit around cultural tourism, culture and heritage. Authorship is relatively fragmented; there is an overrepresentation of the Northeast Region of Brazil. In the references, there is a distinct social sciences orientation; there are relatively few authors and texts concerned with cultural tourism as a market segment. Margarita Barretto's dominance and centrality in the intellectual structure is clear. Concerning the impact, the cluster has an average of actual citations per article just below that verified for the field.

Keywords: Cultural tourism; Bibliometric and social network analysis; Authorship; Intellectual structure; Impact.

\section{Introdução}

A palavra "turismo" é utilizada no linguajar cotidiano, inclusive em situações que não estão contempladas em suas definições científicas mais utilizadas. É já comum ouvir de pessoas que elas fizeram turismo na própria cidade onde vivem, quando, por exemplo, passaram o dia no núcleo antigo, a visitar um museu ou centro cultural. O neologismo "turistar" tem sido muito utilizado, principalmente por pessoas mais jovens, para o ato de fazer atividades similares às presentes durante a experiência de turismo, mesmo que elas tenham sido feitas na própria cidade onde se vive.

É possível distinguir três dimensões do turismo, para além de sua utilização no linguajar cotidiano. Em primeiro lugar, há o fenômeno do turismo, o qual ocorre durante as viagens das pessoas, pelos mais

* Universidade de São Paulo (Brasil); E-mail: afontan@usp.br; https://orcid.org/0000-0002-8291-1654

** Universidade de São Paulo (Brasil); E-mail: luciano.digiampietri@gmail.com; https://orcid.org/0000-0003-4890-1548 
variados motivos. Ou seja, o turismo é um fenômeno do mundo exterior. Em segundo lugar, há o estudo e a pesquisa do turismo, os quais resultam, entre outras coisas, em um conjunto de publicações. Por fim, há a educação e o treinamento em turismo, os quais englobam desde cursos técnicos, como, por exemplo, os de formação de guias, até os programas de pós-graduação stricto sensu em turismo (Tribe, 1997).

Assim como ocorre na Administração, conforme retratado por Bertero et al. (1999), o campo de conhecimento de turismo não passou também por um período de "gestação," dado que seus pesquisadores e profissionais formados foram sempre chamados a resolver problemas concretos, bem como para desenvolver novos produtos e inovações no mercado. Ou seja, não houve, em seu início, um espaço suficiente de fundamentação teórica e de reflexão, longe e insulado das pressões de mercado.

Nos últimos anos, tem-se verificado expressivo crescimento da epistemologia da pesquisa em turismo, como atestam Benckendorff e Zehrer (2013) e Koseoglu et al. (2016). Dentro desse crescimento, destaca-se o uso da bibliometria e da análise de redes sociais, que, segundo Koseoglu et al. (2016), consistem em técnicas e métodos capazes de medir e avaliar o estado atual e a trajetória de uma determinada ciência, disciplina ou campo de conhecimento, por meio da utilização, dentre outras coisas, de citações, referências bibliográficas e palavras-chave. Em suma, a bibliometria e a análise de redes sociais permitem responder as seguintes perguntas:

[...] (a) Qual é a estrutura intelectual da disciplina, e como ela evolui? (b) Qual é a estrutura social da disciplina? (c) Quais são as estruturas conceituais da disciplina? (d) Qual é a melhor maneira de avaliar a produção resultante de pesquisa? (e) Como devem ser avaliados o impacto de pesquisadores e instituições? (f) Como a disciplina está a progredir em temas abordados, métodos [de pesquisa] empregados e amostras utilizadas? Ao responder essas perguntas, possíveis vieses subjetivos são minimizados, e inferências de especialistas são validadas, levando a escolas de pensamento, e a que conexões inter-relacionadas entre elas sejam delineadas. (Koseoglu et al., 2016: 181, tradução nossa)

O presente artigo apresenta uma análise bibliométrica e de redes sociais do campo de turismo no Brasil, considerando-o como o conjunto de artigos publicados em 16 periódicos brasileiros de turismo. Por meio das palavras-chave de cada artigo, é descrita e avaliada a trajetória do supracitado campo, no período 1990-2018, bem como se aprofunda o agrupamento centrado na palavra-chave "turismo cultural."

Como objeto de estudo, trabalha-se com a totalidade de artigos publicados nas revistas científicas brasileiras de turismo, no período 1990-2018. Segue-se o que é mais comum de encontrar nos estudos bibliométricos de turismo, a saber: consideraram-se, para análise, os artigos completos, unicamente, com a exclusão de editoriais, resenhas, entrevistas e todo o resto (Benckendorff \& Zehrer, 2013; Strandberg et al., 2018; Racherla \& $\mathrm{Hu}, 2010)$.

Jamal et al. (2008) e McKercher (2005) indicam que não se deve restringir o estudo bibliométrico a uma fração muito diminuta do campo de conhecimento, em virtude do risco de os resultados da pesquisa não serem representativos. Contudo, é comum encontrar pesquisas que limitam o estudo aos periódicos avaliados como os mais importantes, casos de Ye et al. (2013), Koc e Boz (2014) e Kirilenko e Stepchenkova (2018). Para evitar esse problema, o presente artigo pesquisa um amplo conjunto de periódicos brasileiros de turismo, os quais cumprem, simultaneamente, quatro requisitos.

O primeiro requisito é o periódico ser brasileiro, e ter o sistema de dupla avaliação cega por pares para a publicação de artigos. O segundo é a revista científica ser, apenas, de turismo. Nesse caso, excluíram-se periódicos como, por exemplo, a Marketing \& Tourism Review e a Revista Reuna, a qual se define como uma revista de administração pública e de empresas, contabilidade e turismo. Isso foi feito para evitar a inclusão de artigos que não trabalham com o turismo.

O terceiro requisito é o periódico estar classificado, em fevereiro de 2019, no Qualis Periódicos, Área Administração Pública e de Empresas, Ciências Contábeis e Turismo, com, pelo menos, B5 nas classificações de periódicos (quadriênio 2013-2016) ${ }^{1}$. Por fim, o periódico precisava estar ativo até, pelo menos, o final do ano de 2016.

Por meio desses quatro requisitos, 16 periódicos brasileiros de turismo qualificaram-se para a pesquisa, a saber: a) Anais Brasileiros de Estudos Turísticos (ABET); b) Applied Tourism (AT); c) Caderno de Estudos e Pesquisas do Turismo (CEPT); d) CULTUR - Revista de Cultura e Turismo (CULTUR); e) Caderno Virtual de Turismo (CVT); f) Revista Acadêmica Observatório de Inovação do Turismo (RAOIT); g) Revista Brasileira de Ecoturismo (RBE); h) Revista Brasileira de Pesquisa em Turismo (RBPT); i) Revista Iberoamericana de Turismo (RITUR); j) Revista Latino-Americana de Turismologia (RLAT); k) Revista Rosa dos Ventos (RRV); 1) Revista de Turismo Contemporâneo (RTC); m) Revista Turismo: 
Estudos e Práticas (RTEP); n) Revista Turismo - Visão e Ação (RTVA); o) Turismo em Análise (TA); e p) Turismo e Sociedade (TS).

O presente artigo tem dois objetivos gerais. Para ambos, foram utilizadas, única e tão somente, as palavras-chave dos artigos para a construção e delimitação dos agrupamentos. O primeiro consiste em descrever e analisar a trajetória do agrupamento de turismo cultural, o que inclui, entre outras coisas, a entrada e saída de palavras-chave dele, o número de artigos e as eventuais ligações com outros agrupamentos. Trabalha-se com três períodos de tempo (1990-1999, 1990-2009 e 1990-2018).

O segundo objetivo geral toma o agrupamento de turismo cultural no período 1990-2018, o qual é composto por "turismo cultural", "cultura," "patrimônio cultural," "patrimônio," "identidade," "memória" e "museus." $\mathrm{Na}$ autoria, verifica-se quais são os autores e instituições mais produtivos, assim como, tomando a sede destas, como a produção se distribui entre as unidades da federação e entre o Brasil e países estrangeiros. Pensando no conjunto de artigos publicados, cumpre ver a distribuição entre os 16 periódicos brasileiros de turismo, comparando-a com a do campo como o todo, e verificar o porquê desses resultados.

No impacto (citações), cumpre ver o desempenho do agrupamento de turismo cultural, em relação aos 3.887 artigos do campo de turismo no Brasil. Além disso, cumpre analisar, individualmente, os artigos do agrupamento pertencentes ao conjunto de artigos com mais alto impacto do campo de turismo no Brasil. Por fim, cumpre verificar a estrutura intelectual do agrupamento, por meio das referências bibliográficas de seus artigos. Isso implica em verificar os autores, as obras e as revistas científicas mais citadas, assim como aquelas citadas frequentemente em conjunto.

Para ambos os objetivos gerais, cumpre destacar e comentar não apenas as presenças e as relações existentes, mas também as lacunas e os silêncios. Cumpre, dessa forma, questionar, sempre que possível, quais resultados eram esperados para o agrupamento de turismo cultural, mas que não apareceram na pesquisa.

$\mathrm{O}$ artigo justifica-se por meio de três pontos. Em primeiro lugar, verifica-se que para o Brasil, assim como para vários países em desenvolvimento e/ou cientificamente periféricos, há parte considerável de sua produção científica que não é contemplada pelas bases de dados internacionais. Isso é resultado, principalmente, de a produção científica estar concentrada em periódicos nacionais e regionais, o que faz com que seja mais difícil sua descrição e análise, por meio de estudos bibliométricos (Leta \& Lewison, 2003). Esse parece ser o caso do campo de turismo no Brasil.

Segundo, como bem argumenta McKercher (2005), os artigos publicados em periódicos, que utilizam o sistema de avaliação cega por pares, são o elemento mais importante para a avaliação da qualidade de uma pesquisa, de um pesquisador e de uma instituição. As revistas científicas constituem-se em um objeto de estudo, cuja análise é capaz de apontar a trajetória e os rumos de um campo de conhecimento, acadêmica e profissionalmente (Xiao \& Smith, 2006).

Por fim, a bibliometria e a análise de redes sociais permitem que os pesquisadores estudem o turismo como um sistema de construção de conhecimento (Kirilenko \& Stepchenkova, 2018).

\section{Revisão de literatura}

A partir da revisão de literatura analítica, Benckendorff e Zehrer (2013) caracterizam o turismo de três formas, a saber: a) turismo como campo de conhecimento fragmentado e interdisciplinar; b) turismo como campo de conhecimento que não conta com uma abordagem teórica unificada, mas sim abordagens teóricas múltiplas, derivadas e advindas do conjunto de disciplinas que trabalham com o fenômeno do turismo; e c) "[...] fase de fertilização pós-disciplinar, e pode ser descrito como um campo fragmentado e coerente [...]" (Benckendorff \& Zehrer, 2013: 123, tradução nossa).

Tribe (2010) aponta que o campo de turismo é formado por uma comunidade heterogênea e, em certos pontos, divergente entre si, o que resulta na contribuição de uma grande variedade de teorias, abordagens e disciplinas contributivas.

Utilizando-se de Biglan (1973), Laws e Scott (2015) descrevem o turismo como um tipo específico de campo de conhecimento. Biglan (1973) constrói sua tipologia por meio das seguintes dimensões: a) até qual ponto existe ou não um paradigma?; b) o objeto de estudo é mais "puro" e teórico ou mais prático e aplicado?; e c) o envolvimento se dá mais com sistemas vivos ou inertes? Segundo Laws e Scott (2015), o turismo é um campo soft (não há nenhum paradigma dominante), aplicado (há forte ligação com o mercado profissional) e inerte, pontos que explicam sua heterogeneidade e falta de teorias e metodologias de pesquisa dominantes.

Como bem sintetizam Mulet-Forteza et al. (2019), a bibliometria é um meio para a análise da trajetória da estrutura social, da estrutura intelectual e dos conceitos e definições-chave de uma 
ciência, disciplina ou campo. A bibliometria tem, como objeto de estudo, os resultados publicados da pesquisa - monografias, dissertações e teses, artigos de periódico, livros etc. -, e seu emprego é baseado em métodos quantitativos.

A análise de redes sociais não se constitui em uma teoria; trata-se de um conjunto de técnicas e métodos para a análise e avaliação de estruturas sociais e intelectuais de uma ciência, disciplina ou campo (Otte \& Rousseau, 2002).

Ao invés de se centrar nas características individuais dos elementos em questão, o foco da análise de redes são as relações estabelecidas entre eles. A análise de redes permite a verificação da estrutura de uma ciência, disciplina ou campo, o surgimento, consolidação e declínio de temas, metodologias e teorias, o padrão de coautorias e outros pontos mais (Benckendorff, 2009; Benckendorff \& Zehrer, 2013).

Por exemplo, Benckendorff (2009) busca identificar agrupamentos de temas, tópicos e objetos de estudo, por meio da análise de redes das palavras-chave dos artigos publicados por pesquisadores australianos e neozelandeses nos Annals of Tourism Research e Tourism Management, no período 1994-2007.

\section{Metodologia de pesquisa}

A metodologia de pesquisa baseia-se em seis etapas, a saber: a) coleta de dados; b) verificação e desambiguação de nomes; c) construção e delimitação dos agrupamentos; d) cálculo de índices e de métricas e montagem de rankings; e) construção de redes sociais (autoria) e de redes de referências bibliográficas (autores, obras e revistas científicas); e f) análise qualitativa dos dados, rankings e grafos criados.

No período 1990-2018, o campo de turismo no Brasil é composto por cinco agrupamentos (turismo cultural, destino turístico, ecoturismo, sustentabilidade e hospitalidade). Dado que todos compartilham procedimentos metodológicos comuns, pois partem do mesmo banco de dados, e usam as mesmas ferramentas computacionais desenvolvidas pelos autores, apresenta-se, nesse artigo, a metodologia de pesquisa de forma resumida. Para os leitores interessados em ler a metodologia de pesquisa completa, recomenda-se Köhler e Digiampietri (2021), os quais abordam o agrupamento de hospitalidade.

\subsection{Coleta de dados}

Por meio dos arquivos (.pdf) descarregados dos sítios eletrônicos de cada um dos 16 periódicos brasileiros de turismo, foram coletados dados referentes à autoria e às referências bibliográficas de 3.887 artigos, publicados no período 1990-2018.

As referências bibliográficas foram classificadas nas seguintes categorias: a) Artigo de periódico (campo de turismo); b) Artigo de periódico (outros); c) Livro; d) Capítulo de livro; e) Monografia (mestrado/ doutorado); f) Comunicação - art. completo anais evento; e g) Outros.

A coleta das citações foi feita no Google Acadêmico, A utilização do Google Acadêmico tem sido defendida por muitos autores atuantes no campo de turismo, em virtude de muitas de suas revistas não fazerem parte de índices de impacto (Jamal et al., 2008; McKercher, 2008; Hall, 2011; Strandberg et al., 2018; Law \& Veen, 2008; Koseoglu et al., 2016). A ferramenta lista todas as citações recebidas pelo trabalho em análise, proporcionando uma análise mais rica do que aquela possível por vários índices de impacto, os quais listam, apenas, as citações feitas por artigos de periódico.

Para toda e qualquer citação, foram aplicados três filtros, a saber: a) autocitação (há, no mínimo, um autor em comum entre o trabalho citado e o que o cita; b) erro (o documento que a ferramenta aponta que cita o artigo não existe, ou ele existe, mas não cita o artigo, diferentemente de o que o Google Acadêmico aponta); e c) redundância (o documento que cita aparece duas ou mais vezes na lista do Google Acadêmico).

Assim como foi feito para as referências bibliográficas, as citações foram classificadas em uma de sete categorias.

\subsection{Verificação e desambiguação de nomes.}

Todo o processo de verificação e desambiguação de nomes foi feito de maneira manual, por meio de sucessivas rodadas de revisão e correção. Isso permitiu dar mais segurança ao conjunto de dados trabalhados e apresentados nesse artigo.

A verificação e a desambiguação de nomes foram feitas para a autoria, as referências bibliográficas e as citações. O caso de alguns livros é digno de nota. Com a finalidade de verificar a importância de alguns livros na estrutura intelectual do campo de turismo no Brasil, foram reunidas as versões em português e em inglês de vários volumes. 


\subsection{Construção e delimitação dos agrupamentos.}

No presente artigo, os agrupamentos de palavras-chave foram construídos a partir de uma adaptação do método de Grauwin e Jensen (2011). O método original foi desenvolvido para agrupar artigos utilizando uma medida de similaridade, chamada de acoplamento bibliográfico (bibliographic coupling) (Kessler, 1963), a qual atribue uma similaridade a cada par de artigos, com base nas referências bibliográficas compartilhadas por eles (Koseoglu et al., 2016).

A adaptação utiliza no presente artigo calcula a similaridade entre trabalhos, com base nas palavras-chave compartilhadas por eles, assumindo que quanto mais alto o número de palavras-chaves compartilhadas, mais alta será a chance de os trabalhos possuírem temática semelhante.

O método de construção de agrupamentos é sensível tanto a palavras-chave muito frequentes, mas com baixo poder descritivo, as quais podem levar à criação de grupos com múltiplas temáticas, quanto a palavras-chave com frequência muito baixa, que podem levar à criação de grupos muito pequenos e artificiais. Assim, as palavras-chave "turismo" e "Brasil" foram desconsideradas, por sua alta frequência e baixo poder descritivo. Para cada período de análise, diferentes limiares foram estabelecidos para a exclusão de palavras-chave com baixa frequência e baixa co ocorrência. Para 1990-1999, foram descartadas as palavras-chave com frequência mais baixa do que três e co ocorrência mais baixa do que dois. Para 1990-2009, foram descartas as palavras-chave com frequência abaixo de cinco e co ocorrência abaixo de três. Já para 1990-2018, os limiares foram iguais a 20 e cinco, respectivamente.

Para a construção dos agrupamentos, foram considerados apenas os artigos que têm a palavra-chave com mais alta frequência, e/ou que contêm duas ou mais palavras-chave quaisquer do agrupamento.

\subsection{Cálculo de índices e de métricas e montagem de rankings.}

Dado que o agrupamento de turismo cultural tem, apenas, 139 artigos (1990-2018), optou-se pelo cálculo de um pequeno conjunto de índices e de métricas. Avaliou-se ser mais proveitoso a análise qualitativa das tabelas e dos grafos construídos, a fim de verificar as particularidades desse agrupamento.

Foi utilizado o método da contagem simples, por meio do qual cada elemento (por exemplo, autor) recebe um ponto por artigo assinado, havendo ou não coautores. As palavras-chave e as referências bibliográficas foram contadas, também, por meio da contagem simples.

Para as citações, foram calculados a média, a mediana e o desvio-padrão, tanto para o agrupamento de turismo cultural quanto para o campo como um todo, assim como a contagem simples. Para todo e qualquer artigo, foram calculadas as citações reais, as quais são iguais às citações nominais subtraídas de autocitações, erros e redundâncias.

\subsection{Construção de redes sociais (autoria) e de redes de referências bibliográficas (autores, obras e revistas científicas).}

Foram construídas as seguintes redes: a) palavras-chave; b) referências bibliográficas - autores; c) referências bibliográficas - obras; e d) referências bibliográficas - revistas científicas. Dado o baixo número de artigos no agrupamento de turismo cultural, as redes construídas para os dados de autoria dos artigos (autores, instituições, unidades da federação e países) não são mostrados, dado que não expõem relações significativas de coautoria.

A literatura não indica pontos de corte à análise de redes sociais, de aplicação universal. Desse modo, foram definidos pontos de corte para o conjunto de redes construídas (autores, obras e revistas científicas), levando-se em conta, simultaneamente, os cinco agrupamentos. Por meio da utilização de diversos parâmetros, foram definidos os seguintes pontos de corte para a inclusão nas redes de autores, obras e revistas científicas (referências bibliográficas): a) frequência mínima de 10\%, com arredondamento para baixo (13 de 139 artigos); e/ou b) aresta com, no mínimo, 5\% dos artigos, com arredondamento para baixo (6 de 139 artigos).

Para a construção das redes - e, consequentemente, dos gráficos -, foram utilizadas ferramentas computacionais desenvolvidas pelos autores do presente artigo.

\subsection{Análise qualitativa dos dados, rankings e grafos criados.}

Para as várias tabelas e grafos criados, foi feita uma análise qualitativa, a fim de compreender as particularidades do agrupamento de turismo cultural. No caso dos autores, acessou-se seu Currículo Lattes, se existente, a fim de avaliar sua produção científica. Já para as obras específicas, havia já o conhecimento prévio de quase todas elas. Para as até então não lidas, foi feita uma leitura transversal. Todas as revistas 
científicas constantes do ranking e/ou do grafo da estrutura intelectual (referências bibliográficas) do agrupamento de turismo cultural eram já de conhecimento dos autores do presente artigo.

Foi realizada, também, a classificação dos artigos dos agrupamentos, por meio de Tribe $(1997,2010)$, em estudos ligados a negócios turísticos (tourism business studies) e em estudos não ligados a negócios turísticos (non-business tourism studies). Contudo, Tribe $(1997,2010)$ não fornece parâmetros para tal classificação; logo, ela foi feita a critério dos autores do presente artigo.

\section{Resultados}

No período 1990-2018, os 16 periódicos brasileiros de turismo publicaram 3.887 artigos, que, em conjunto, apresentam 108.595 referências bibliográficas, das quais 69.022 únicas, e foram citados 10.882 vezes por outros trabalhos. A Tabela 1 traz os dados básicos do objeto de estudo, divididos para os períodos 1990-1999, 1990-2009 e 1990-2018.

Os gráficos 1, 2 e 3 trazem os agrupamentos do campo de turismo no Brasil para os períodos 1990-1999, 1990-2009 e 1990-2018, respectivamente. O tamanho dos nós representa a quantidade de artigos, ao passo que a grossura das arestas indica a quantidade de artigos que têm, conjuntamente, as duas palavras-chave em questão.

Para fins de visualização, para cada agrupamento, manteve-se, sempre que possível, o padrão de cores, ao longo dos períodos. Foram apresentados os rótulos apenas da palavra-chave com mais alta frequência em cada um deles, com exceção do de turismo cultural, objeto do presente artigo. As arestas externas (entre palavras-chave de agrupamentos diferentes) têm cor preta. Por fim, foram colocadas palavras-chave isoladas apenas com alta frequência.

Tabela 1: Campo de turismo no Brasil - dados básicos (1990-1999, 1990-2009 e 1990-2018)

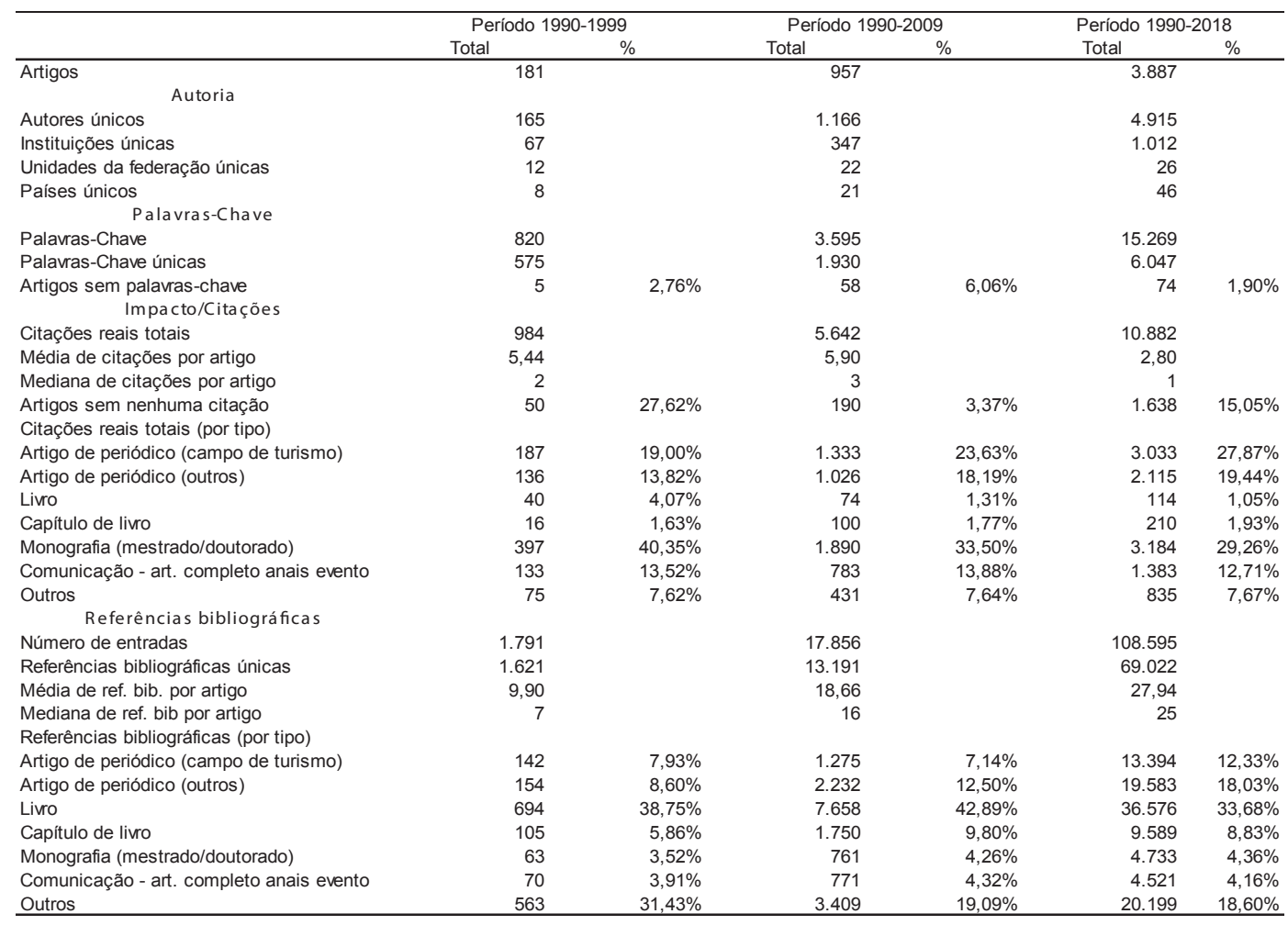

Fonte: Köhler e Digiampietri (2021). 
Gráfico 1: Campo de turismo no Brasil - agrupamentos (1990-1999)

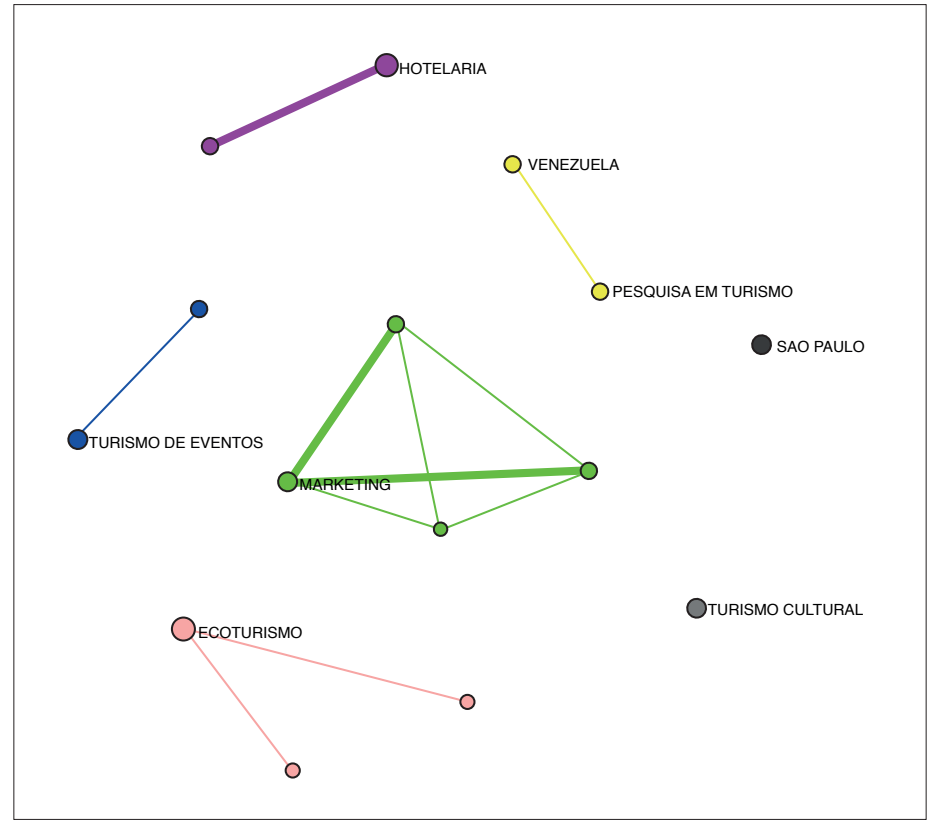

Fonte: Elaboração própria.

Gráfico 2: Campo de turismo no Brasil - agrupamentos (1990-2009)

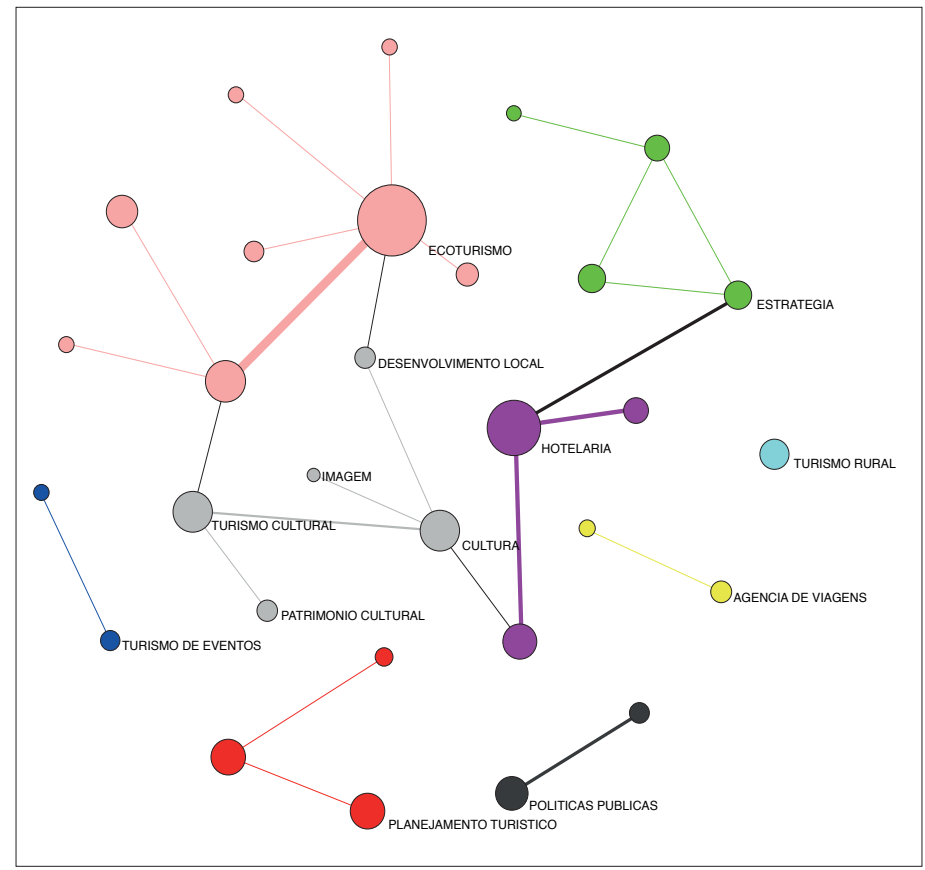

Fonte: Elaboração própria. 
Gráfico 3: Campo de turismo no Brasil - agrupamentos (1990-2018)

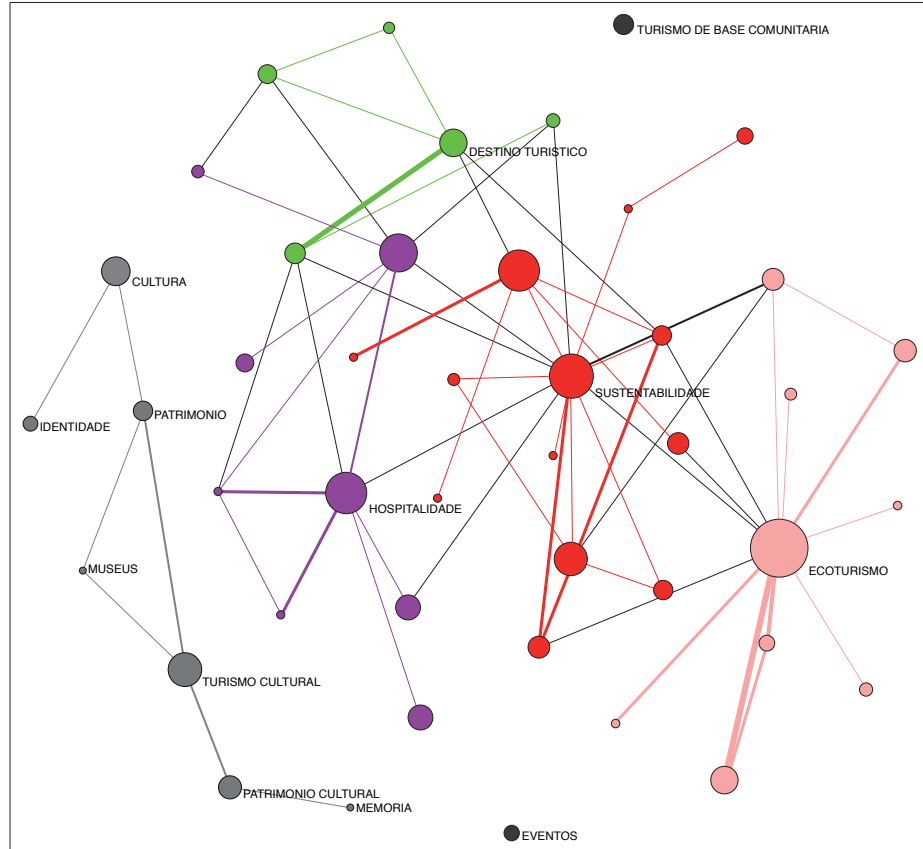

Fonte: Elaboração própria.

A Tabela 2 traz uma série de dados básicos para cada agrupamento (1990-2018); isso permite a análise do agrupamento de turismo cultural, em perspectiva comparada:

Tabela 2: Campo de turismo no Brasil - dados básicos por agrupamento (1990-2018)

\begin{tabular}{|c|c|c|c|c|c|c|c|c|c|c|c|c|}
\hline & \multicolumn{2}{|c|}{ Turismo Cultural } & \multicolumn{2}{|c|}{ Ecoturismo } & \multicolumn{2}{|c|}{ Destino Turistico } & \multicolumn{2}{|c|}{ Hospitalidade } & \multicolumn{2}{|c|}{ Sustentabilidade } & \multicolumn{2}{|c|}{ Universo de artigos } \\
\hline & Total & $\%$ & Total & $\%$ & Total & $\%$ & Total & $\%$ & Total & $\%$ & Total & $\%$ \\
\hline Artigos & 139 & & 208 & & 98 & & 157 & & 213 & & 3.887 & \\
\hline Autores únicos & 219 & & 438 & & 170 & & 240 & & 433 & & 4.915 & \\
\hline Instituições únicas & 98 & & 145 & & 77 & & 91 & & 165 & & 1.012 & \\
\hline Unidades da federaçäo únicas & 24 & & 24 & & 17 & & 21 & & 23 & & 26 & \\
\hline $\begin{array}{l}\text { Países únicos } \\
\qquad / \mathrm{mpacto} / \text { Citacôes }\end{array}$ & 11 & & 11 & & 9 & & 10 & & 14 & & 46 & \\
\hline Citações reais totais & 366 & & 661 & & 323 & & 395 & & 746 & & 10.882 & \\
\hline Média de citaçöes por artigo & 2,63 & & 3,18 & & 3,30 & & 2,52 & & 3,50 & & 2,80 & \\
\hline Mediana de citações por artigo & 1 & & 2 & & 1 & & 1 & & 1 & & 1 & \\
\hline $\begin{array}{l}\text { Artigos sem nenhuma citação } \\
\text { Citações reais totais (por tipo) }\end{array}$ & 63 & $45,32 \%$ & 65 & $31,25 \%$ & 39 & $39,80 \%$ & 72 & $45,86 \%$ & 95 & $44,60 \%$ & 1.638 & $42,14 \%$ \\
\hline Artigo de periódico (campo de turismo) & 79 & $21,58 \%$ & 185 & $27,99 \%$ & 112 & $34,67 \%$ & 134 & $33,92 \%$ & 216 & $28,95 \%$ & 3.033 & $27,87 \%$ \\
\hline Artigo de periódico (outros) & 67 & $18,31 \%$ & 170 & $25,72 \%$ & 53 & $16,41 \%$ & 74 & $18,73 \%$ & 148 & $19,84 \%$ & 2.115 & $19,44 \%$ \\
\hline Livo & 2 & $0,55 \%$ & 9 & $1,36 \%$ & 3 & $0,93 \%$ & 5 & $1,27 \%$ & 9 & $1,21 \%$ & 114 & $1,05 \%$ \\
\hline Capitulo de livo & 12 & $3,28 \%$ & 10 & $1,51 \%$ & 5 & $1,55 \%$ & 9 & $2,28 \%$ & 11 & $1,47 \%$ & 210 & $1,93 \%$ \\
\hline Monografia (mestrado/doutorado) & 114 & $31,15 \%$ & 164 & $24,81 \%$ & 84 & $26,01 \%$ & 94 & $23,80 \%$ & 210 & $28,15 \%$ & 3.184 & $29,26 \%$ \\
\hline Comunicação - art. completo anais evento & 50 & $13,66 \%$ & 71 & $10,74 \%$ & 30 & $9,29 \%$ & 46 & $11,65 \%$ & 95 & $12,73 \%$ & 1.383 & $12,71 \%$ \\
\hline Outros & 42 & $11,48 \%$ & 52 & $7,87 \%$ & 36 & $11,15 \%$ & 33 & $8,35 \%$ & 57 & $7,64 \%$ & 835 & $7,67 \%$ \\
\hline Referências bibliográficas & & & & & & & & & & & & \\
\hline Número de entradas & 3.389 & & 5.583 & & 3.704 & & 4.516 & & 6.312 & & 108.595 & \\
\hline Referências bibliográficas únicas & 2.782 & & 4.334 & & 2.999 & & 3.547 & & 5.232 & & 69.022 & \\
\hline Média de ref. bib. por artigo & 24,38 & & 26,84 & & 37,80 & & 28,76 & & 29,63 & & 27,94 & \\
\hline $\begin{array}{l}\text { Mediana de ref. bib por artigo } \\
\text { Referências bibliográícas (por tipo) }\end{array}$ & 23 & & 23,5 & & 33 & & 27 & & 26 & & 25 & \\
\hline Artigo de periódico (campo de turismo) & 245 & $7,23 \%$ & 450 & $8,06 \%$ & 893 & $24,11 \%$ & 389 & $8,61 \%$ & 769 & $12,18 \%$ & 13.394 & $12,33 \%$ \\
\hline Artigo de periódico (outros) & 351 & $10,36 \%$ & 853 & $15,28 \%$ & 706 & $19,06 \%$ & 860 & $19,04 \%$ & 1.035 & $16,40 \%$ & 19.583 & $18,03 \%$ \\
\hline Livo & 1.437 & $42,40 \%$ & 1.681 & $30,11 \%$ & 1035 & $27,94 \%$ & 1804 & $39,95 \%$ & 1.979 & $31,35 \%$ & 36.576 & $33,68 \%$ \\
\hline Capitulo de livo & 359 & $10,59 \%$ & 634 & $11,36 \%$ & 208 & $5,62 \%$ & 463 & $10,25 \%$ & 612 & $9,70 \%$ & 9.589 & $8,83 \%$ \\
\hline Monografia (mestrado/doutorado) & 138 & $4,07 \%$ & 338 & $6,05 \%$ & 161 & $4,35 \%$ & 208 & $4,61 \%$ & 276 & $4,37 \%$ & 4.733 & $4,36 \%$ \\
\hline Comunicaçã̃o - art. completo anais evento & 100 & $2,95 \%$ & 252 & $4,51 \%$ & 157 & $4,24 \%$ & 144 & $3,19 \%$ & 287 & $4,55 \%$ & 4.521 & $4,16 \%$ \\
\hline Outros & 759 & $22,40 \%$ & 1.375 & $24,63 \%$ & 544 & $14,69 \%$ & 648 & $14,35 \%$ & 1.354 & $21,45 \%$ & 20.199 & $18,60 \%$ \\
\hline
\end{tabular}

Fonte: Köhler e Digiampietri (2021). 
A Tabela 3 traz a lista com os autores com mais alta produção do agrupamento de turismo cultural, assim como a Tabela 4 apresenta o mesmo tipo de dados para as instituições:

Tabela 3: Agrupamento de turismo cultural - autores com mais alta produção (1990-2018)

\begin{tabular}{|c|c|c|c|c|c|}
\hline \multirow[b]{3}{*}{ Nome do autor } & \multicolumn{5}{|c|}{ Campo de turismo no Brasil - 16} \\
\hline & \multicolumn{2}{|c|}{ Agrupamento de turismo cultural } & \multicolumn{2}{|c|}{ periódicos } & \multirow{2}{*}{$\begin{array}{c}\% \text { do agrupamento } \\
\text { sobre o campo }\end{array}$} \\
\hline & Posição & Artigos & Posição & Artigos & \\
\hline Karoliny Diniz Carvalho & $1^{\circ}$ & 7 & $20^{\circ}$ & 14 & $50,00 \%$ \\
\hline Pedro de Alcântara Bittencourt César & $2^{\circ}$ & 4 & $13^{\circ}$ & 19 & $21,05 \%$ \\
\hline Silvana Pirillo Ramos & $3^{\circ}$ & 3 & $107^{\circ}$ & 7 & $42,86 \%$ \\
\hline Mario Jorge Pires & $3^{\circ}$ & 3 & $133^{\circ}$ & 6 & $50,00 \%$ \\
\hline Janete Ruiz de Macedo & $3^{\circ}$ & 3 & $133^{\circ}$ & 6 & $50,00 \%$ \\
\hline Roselys Izabel Correa dos Santos & $3^{\circ}$ & 3 & $176^{\circ}$ & 5 & $60,00 \%$ \\
\hline Neus Crous-Costa & $3^{\circ}$ & 3 & $176^{\circ}$ & 5 & $60,00 \%$ \\
\hline
\end{tabular}

Fonte: Elaboração própria.

Tabela 4: Agrupamento de turismo cultural - instituições com mais alta produção (1990-2018)

\begin{tabular}{lccccrr}
\hline & \multicolumn{2}{c}{$\begin{array}{c}\text { Agrupamento de turismo } \\
\text { cultural }\end{array}$} & \multicolumn{2}{c}{$\begin{array}{c}\text { Campo de turismo no Brasil - 16 } \\
\text { periódicos }\end{array}$} & $\begin{array}{c}\text { \% do agrupamento } \\
\text { sobre o campo }\end{array}$ \\
Nome da instituição & Posição & Artigos & & Posição & Artigos & 82 \\
\hline Universidade Estadual de Santa Cruz & $1^{\circ}$ & 14 & $9^{\circ}$ & $17,07 \%$ \\
Universidade de São Paulo & $2^{\circ}$ & 9 & $1^{\circ}$ & 251 & $3,59 \%$ \\
Universidade do Vale do Itajaí & $3^{\circ}$ & 6 & $2^{\circ}$ & 219 & $2,74 \%$ \\
Universidade de Caxias do Sul & $4^{\circ}$ & 5 & $5^{\circ}$ & 136 & $3,68 \%$ \\
\hline
\end{tabular}

Fonte: Elaboração própria.

É possível comparar a participação desses autores e instituições no agrupamento de turismo cultural com a no campo de turismo no Brasil, assim como o quanto da produção do autor ou instituição liga-se a aquele. 
A Tabela 5 mostra a distribuição da produção do agrupamento de turismo cultural e do campo de turismo no Brasil, entre as unidades da federação e grandes regiões do Brasil. Já a Tabela 6 traz os principais países responsáveis pela produção do supracitado agrupamento:

Tabela 5: Agrupamento de turismo cultural - unidades da federação e grandes regiões do Brasil com mais alta produção (1990-2018)

\begin{tabular}{|c|c|c|c|c|c|}
\hline \multirow{2}{*}{$\begin{array}{l}\text { Nome da unidade da federação ou } \\
\text { grande região }\end{array}$} & \multicolumn{2}{|c|}{$\begin{array}{c}\text { Agrupamento de turismo } \\
\text { cultural }\end{array}$} & \multicolumn{2}{|c|}{$\begin{array}{l}\text { Campo de turismo no Brasil - } \\
16 \text { periódicos }\end{array}$} & \multirow{2}{*}{$\begin{array}{l}\% \text { do agrupamento } \\
\text { sobre o campo }\end{array}$} \\
\hline & Posição & Artigos & Posição & Artigos & \\
\hline São Paulo & $1^{\circ}$ & 23 & $1^{\circ}$ & 667 & $3,45 \%$ \\
\hline Bahia & $2^{\circ}$ & 16 & $8^{\circ}$ & 157 & $10,19 \%$ \\
\hline Rio Grande do Sul & $3^{\circ}$ & 9 & $4^{\circ}$ & 324 & $2,78 \%$ \\
\hline Minas Gerais & $3^{\circ}$ & 9 & $6^{\circ}$ & 313 & $2,88 \%$ \\
\hline Santa Catarina & $5^{\circ}$ & 6 & $2^{\circ}$ & 379 & $1,58 \%$ \\
\hline Paraná & $5^{\circ}$ & 6 & $3^{\circ}$ & 328 & $1,83 \%$ \\
\hline Rio Grande do Norte & $5^{\circ}$ & 6 & $7^{\circ}$ & 221 & $2,71 \%$ \\
\hline Rio de Janeiro & $8^{\circ}$ & 5 & $5^{\circ}$ & 317 & $1,58 \%$ \\
\hline Maranhão & $9^{\circ}$ & 4 & $17^{\circ}$ & 54 & $7,41 \%$ \\
\hline Mato Grosso do Sul & $10^{\circ}$ & 3 & $13^{\circ}$ & 87 & $3,45 \%$ \\
\hline Piauí & $10^{\circ}$ & 3 & $16^{\circ}$ & 61 & $4,92 \%$ \\
\hline Goiás & $10^{\circ}$ & 3 & $19^{\circ}$ & 32 & $9,38 \%$ \\
\hline Alagoas & $10^{\circ}$ & 3 & $20^{\circ}$ & 31 & $9,68 \%$ \\
\hline Paraiba & $14^{\circ}$ & 2 & $10^{\circ}$ & 101 & $1,98 \%$ \\
\hline Pernambuco & $14^{\circ}$ & 2 & $12^{\circ}$ & 90 & $2,22 \%$ \\
\hline Sergipe & $14^{\circ}$ & 2 & $14^{\circ}$ & 70 & $2,86 \%$ \\
\hline Mato Grosso & $14^{\circ}$ & 2 & $22^{\circ}$ & 24 & $8,33 \%$ \\
\hline Distrito Federal & $18^{\circ}$ & 1 & $9^{\circ}$ & 104 & $0,96 \%$ \\
\hline Ceará & $18^{\circ}$ & 1 & $11^{\circ}$ & 92 & $1,09 \%$ \\
\hline Amazonas & $18^{\circ}$ & 1 & $18^{\circ}$ & 34 & $2,94 \%$ \\
\hline Tocantins & $18^{\circ}$ & 1 & $21^{\circ}$ & 25 & $4,00 \%$ \\
\hline Roraima & $18^{\circ}$ & 1 & $23^{\circ}$ & 21 & $4,76 \%$ \\
\hline Espírito Santo & $18^{\circ}$ & 1 & $24^{\circ}$ & 18 & $5,56 \%$ \\
\hline Rondônia & $18^{\circ}$ & 1 & $25^{\circ}$ & 5 & $20,00 \%$ \\
\hline Pará & $25^{\circ}$ & 0 & $15^{\circ}$ & 69 & $0,00 \%$ \\
\hline Acre & $25^{\circ}$ & 0 & $26^{\circ}$ & 1 & $0,00 \%$ \\
\hline Amapá & $25^{\circ}$ & 0 & $27^{\circ}$ & 0 & Não se aplica \\
\hline Região Nordeste & $1^{\circ}$ & 39 & $3^{\circ}$ & 877 & $4,45 \%$ \\
\hline Região Sudeste & $2^{\circ}$ & 38 & $1^{\circ}$ & 1315 & $2,89 \%$ \\
\hline Região Sul & $3^{\circ}$ & 21 & $2^{\circ}$ & 1031 & $2,04 \%$ \\
\hline Região Centro-Oeste & $4^{\circ}$ & 9 & $4^{\circ}$ & 247 & $3,64 \%$ \\
\hline Região Norte & $5^{\circ}$ & 4 & $5^{\circ}$ & 155 & $2,58 \%$ \\
\hline
\end{tabular}

Fonte: Elaboração própria.

Tabela 6: Agrupamento de turismo cultural - países com mais alta produção (1990-2018)

\begin{tabular}{|c|c|c|c|c|c|}
\hline \multirow[b]{2}{*}{ Nome do país } & \multicolumn{2}{|c|}{$\begin{array}{c}\text { Agrupamento de turismo } \\
\text { cultural }\end{array}$} & \multicolumn{2}{|c|}{$\begin{array}{c}\text { Campo de turismo no Brasil - } \\
16 \text { periódicos }\end{array}$} & \multirow{2}{*}{$\begin{array}{c}\text { \% do } \\
\text { agrupamento } \\
\text { sobre o campo }\end{array}$} \\
\hline & Posição & Artigos & Posição & Artigos & \\
\hline Brasil & $1^{\circ}$ & 104 & $1^{\circ}$ & 3147 & $3,30 \%$ \\
\hline Espanha & $2^{\circ}$ & 11 & $2^{\circ}$ & 156 & $7,05 \%$ \\
\hline Portugal & $3^{\circ}$ & 9 & $3^{\circ}$ & 142 & $6,34 \%$ \\
\hline Mexico & $4^{\circ}$ & 4 & $4^{\circ}$ & 139 & $2,88 \%$ \\
\hline Colombia & $5^{\circ}$ & 3 & $14^{\circ}$ & 10 & $30,00 \%$ \\
\hline Argentina & $6^{\circ}$ & 2 & $5^{\circ}$ & 60 & $3,33 \%$ \\
\hline Equador & $6^{\circ}$ & 2 & $7^{\circ}$ & 23 & $8,70 \%$ \\
\hline Franca & $6^{\circ}$ & 2 & $8^{\circ}$ & 21 & $9,52 \%$ \\
\hline Venezuela & $9^{\circ}$ & 1 & $6^{\circ}$ & 26 & $3,85 \%$ \\
\hline Cuba & $9^{\circ}$ & 1 & $11^{\circ}$ & 14 & $7,14 \%$ \\
\hline Uruguai & $9^{\circ}$ & 1 & $12^{\circ}$ & 13 & $7,69 \%$ \\
\hline
\end{tabular}

Fonte: Elaboração própria. 
Por fim, em termos de produção, a Tabela 7 traz a lista com os 16 periódicos do campo de turismo no Brasil, mostrando, em número de artigos, o quanto cada um deles representa do campo como um todo e do agrupamento de turismo cultural, bem como a sobre representação ou a sub-representação daí resultante - nesse último caso, 100\% significa que não há nenhuma delas:

Tabela 7: Agrupamento de turismo cultural - publicação nos 16 periódicos selecionados (1990-2018)

\begin{tabular}{|c|c|c|c|c|c|}
\hline \multirow[b]{2}{*}{ Nome do periódico } & \multicolumn{2}{|c|}{$\begin{array}{c}\text { Agrupamento de turismo } \\
\text { cultural }\end{array}$} & \multicolumn{2}{|c|}{$\begin{array}{c}\text { Campo de turismo no Brasil - } 16 \\
\text { periódicos }\end{array}$} & \multirow{2}{*}{$\begin{array}{c}\text { Representação } \\
\text { (turismo cultural / } \\
\text { campo) }\end{array}$} \\
\hline & Artigos & Porcentagem & Artigos & Porcentagem & \\
\hline ABET & 3 & $2,16 \%$ & 141 & $3,63 \%$ & $59,50 \%$ \\
\hline AT & 0 & $0,00 \%$ & 80 & $2,06 \%$ & $0,00 \%$ \\
\hline CEPT & 2 & $1,44 \%$ & 88 & $2,26 \%$ & $63,55 \%$ \\
\hline CVT & 16 & $11,51 \%$ & 463 & $11,91 \%$ & $96,64 \%$ \\
\hline CULTUR & 23 & $16,55 \%$ & 251 & $6,46 \%$ & $256,24 \%$ \\
\hline RAOIT & 4 & $2,88 \%$ & 189 & $4,86 \%$ & $59,18 \%$ \\
\hline RBE & 4 & $2,88 \%$ & 357 & $9,18 \%$ & $31,33 \%$ \\
\hline RBPT & 8 & $5,76 \%$ & 266 & $6,84 \%$ & $84,10 \%$ \\
\hline RTC & 6 & $4,32 \%$ & 98 & $2,52 \%$ & $171,21 \%$ \\
\hline RITUR & 20 & $14,39 \%$ & 206 & $5,30 \%$ & $271,50 \%$ \\
\hline RLAT & 0 & $0,00 \%$ & 48 & $1,23 \%$ & $0,00 \%$ \\
\hline RRV & 9 & $6,47 \%$ & 311 & $8,00 \%$ & $80,92 \%$ \\
\hline RTEP & 5 & $3,60 \%$ & 117 & $3,01 \%$ & $119,50 \%$ \\
\hline RTVA & 9 & $6,47 \%$ & 438 & $11,27 \%$ & $57,46 \%$ \\
\hline TS & 11 & $7,91 \%$ & 239 & $6,15 \%$ & $128,70 \%$ \\
\hline TA & 19 & $13,67 \%$ & 595 & $15,31 \%$ & $89,30 \%$ \\
\hline TOTAL & 139 & $100 \%$ & 3887 & $100 \%$ & $100,00 \%$ \\
\hline
\end{tabular}

Fonte: Elaboração própria.

Para discutir a estrutura intelectual, são abordados os autores, as obras e as revistas científicas com mais alta frequência, nas referências bibliográficas, e/ou que aparecem nas redes de cocitação. A Tabela 8 traz o ranking de autores, ao passo que o Gráfico 4 apresenta a rede com todas as cocitações relevantes:

Tabela 8: Agrupamento de turismo cultural - autores mais referenciados (1990-2018)

\begin{tabular}{|c|c|c|c|}
\hline Nome do autor & Citações (ref. bib.) & Nome do autor & Citações (ref. bib.) \\
\hline Brasil & & 155 Françoise Choay & 15 \\
\hline Margarita Barretto & & 51 Greg Richards & 15 \\
\hline Néstor García Canclini & & 36 Pedro Paulo A. Funari & 15 \\
\hline UNESCO & & 35 Milton A. dos Santos & 14 \\
\hline Mario Carlos Beni & & 24 Jacques Le Goff & 13 \\
\hline Organização Mundial do Turismo & & 21 José N. Coelho Meneses & 12 \\
\hline Stuart Hall & & 21 Pierre Nora & 11 \\
\hline Reinaldo Dias & & 20 Ada de Freitas M. Dencker & 10 \\
\hline John Urry & & 16 Flávia Roberta Costa & 9 \\
\hline
\end{tabular}

Fonte: Elaboração própria. 


\section{Gráfico 4: Agrupamento de turismo cultural - rede de cocitação de autores (referências bibliográficas) (1990-2018)}

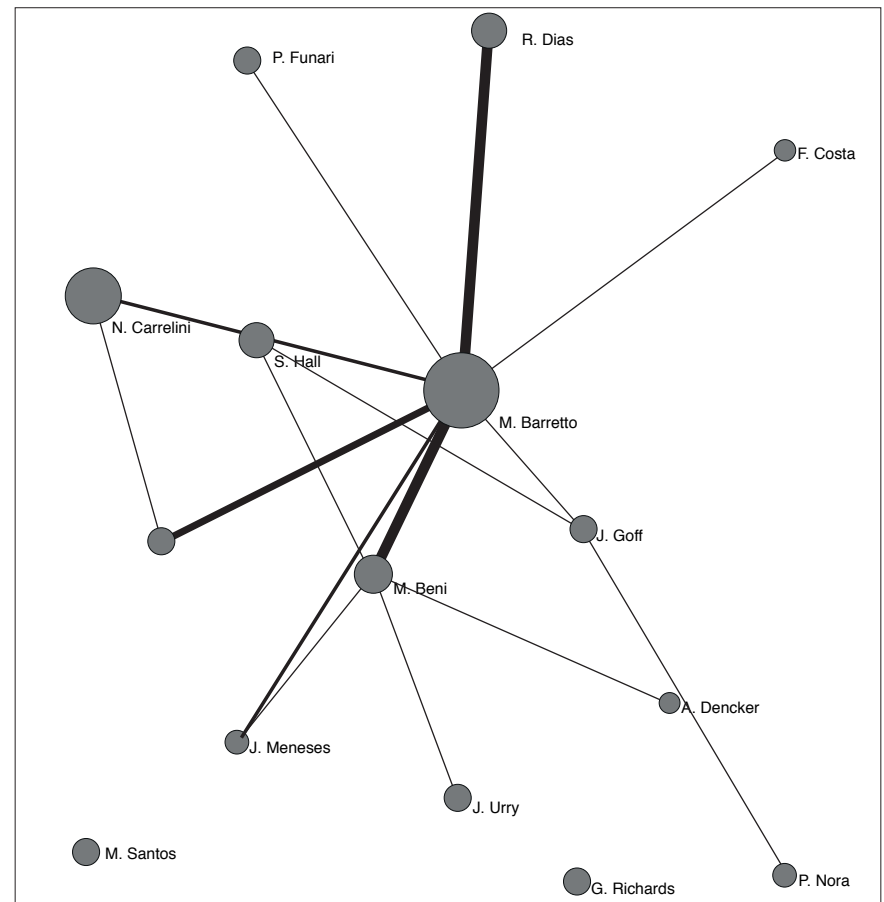

Fonte: Elaboração própria.

Foram retirados, do Gráfico 4, os autores que representam governos e instituições - Brasil, UNESCO e Organização Mundial do Turismo.

A Tabela 9 traz as obras mais citadas, ao passo que o Gráfico 5 ressalta as que são mais citadas conjuntamente. Por fim, a Tabela 10 traz as revistas científicas; apresentam-se, nesse caso, a frequência de vezes nas quais elas aparecem nas referências bibliográficas, bem como o número de artigos do agrupamento de turismo cultural nos quais elas aparecem em, pelo menos, uma referência bibliográfica (doravante denominada de "presença", no presente artigo). Os periódicos que constam em menos de 10\% (arredondamento para baixo) dos artigos, no que concerne a presença, mas que tenham atingido, pelo menos, esse ponto de corte na frequência, aparecem tachados de cinza:

Tabela 9: Agrupamento de turismo cultural - obras mais referenciadas (1990-2018)

\begin{tabular}{lc}
\hline Referência Bibliográfica & Citações (ref. bib.) \\
\hline Barretto (2003) & 24 \\
Beni (1998) & 17 \\
Brasil (2010) & 16 \\
Choay (2006) & 15 \\
Funari e Pinsky (2014) & 15 \\
Urry (2002) & 13 \\
Hall (2004) & 13 \\
Meneses (2013) & 13 \\
Goff (2013) & 11 \\
Dias (2006) & 10 \\
\hline
\end{tabular}

Fonte: Elaboração própria. 
Gráfico 5: Agrupamento de turismo cultural - rede de cocitação de obras (referências bibliográficas) (1990-2018)

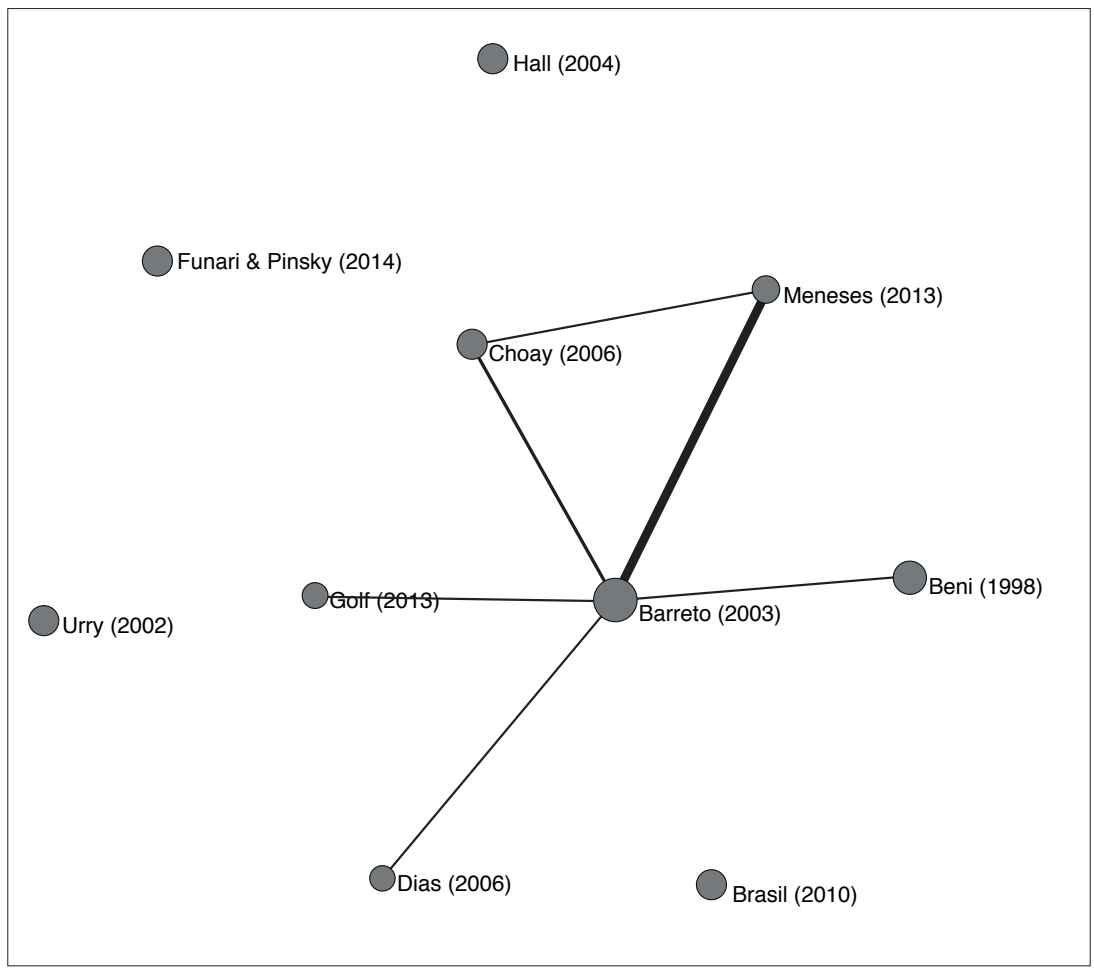

Fonte: Elaboração própria.

Tabela 10: Agrupamento de turismo cultural - revistas científicas mais referenciadas (1990-2018)

\begin{tabular}{lcc}
\hline Nome do periódico & Presença & Frequência \\
\hline Pasos. Revista de Turismo y & 23 & 29 \\
Patrimonio Cultural & 16 & 40 \\
Annals of Tourism Research & 13 & 15 \\
Horizontes Antropológicos & 13 & 17 \\
Revista Turismo - Visão e Ação & & \\
Revista do Patrimônio Histórico e & 10 & 14 \\
Artístico Nacional & 9 & 19 \\
Tourism Management & 9 & 15 \\
Cuadernos de Turismo & 3 & 13 \\
Cahier Espaces & 3 &
\end{tabular}

Fonte: Elaboração própria.

Há poucos periódicos que são citados, conjuntamente, em número relevante. Há apenas dois pares relevantes, a saber: a) Annals of Tourism Research e Tourism Management, com seis artigos; e b) Horizontes Antropológicos e Pasos. Revista de Turismo y Patrimonio Cultural, com também seis artigos. Todas as outras cocitações aparecem em quatro ou menos artigos. 


\section{Discussão de resultados}

A Tabela 1 permite que se vislumbre, em síntese, o significativo crescimento e amadurecimento do campo de turismo no Brasil, notadamente no caso da autoria e das referências bibliográficas. No que concerne estas últimas, a média e a mediana das referências bibliográficas por artigo têm crescimentos de $182,3 \%$ e de $257,1 \%$, respectivamente, do período $1990-1999$ para 1990-2018.

Houve também uma significativa mudança na composição das referências bibliográficas. Em 1990-1999, as referências bibliográficas do tipo "Livro" e "Outros" respondiam por mais de 70\% do total. No caso de "Outros", havia muitos trabalhos de conclusão de curso e documentos institucionais. No período 1990-2018, verifica-se uma diminuição da importância de "Outros", ao passo que os artigos de periódico (de turismo e outros) passaram de 16,53\% (1990-1999) para 30,37\% (1990-2018). Avalia-se como amadurecimento do campo não apenas o crescimento dessas média e mediana, mas também o aumento da importância das revistas científicas nas referências bibliográficas.

A discussão dos resultados está subdividida em cinco subseções, a saber: a) a trajetória do agrupamento de turismo cultural, de 1990-1999 a 1990-2018; b) a produção do agrupamento, por autores, instituições, unidades da federação, grandes regiões e países; c) a estrutura intelectual do agrupamento, por meio das referências bibliográficas de seus artigos; d) a distribuição dos artigos do agrupamento de turismo cultural entre os 16 periódicos do campo de turismo no Brasil; e e) o impacto do agrupamento de turismo cultural.

\subsection{A trajetória do agrupamento de turismo cultural, de 1990-1999 a 1990-2018}

No período 1990-1999, o campo de turismo no Brasil era composto, majoritariamente, pelo periódico TA - a RTVA foi criada apenas em 1998. Há apenas 181 artigos, dos quais cinco não apresentam palavras-chave. Dentro desse quadro, não é de se estranhar, como mostra o Gráfico 1, que haja agrupamentos com poucas palavras-chave, cada um deles, e nenhuma ligação entre si (ausência de arestas externas).

Apesar de "turismo cultural" ser a quinta palavra-chave mais utilizada, com frequência igual a sete, ela não forma nenhum agrupamento, permanecendo isolada. "Cultura" tem frequência igual a três, e está também isolada. De todo modo, os dados do período 1990-1999 precisam ser vistos com cautela, dado que a base de artigos é muito reduzida, e a coleta de dados mostrou que há baixa normalização na utilização de palavras-chave, nesse período.

No período 1990-2009, há a formação de oito agrupamentos, dos quais o centrado na palavra-chave "ecoturismo" é o mais importante. Surgem as primeiras arestas externas, que ligam palavras-chave de agrupamentos diferentes. Dentre os oito existentes, o de turismo cultural é o que mais se liga a outros agrupamentos, o que forma um contraste interessante com o encontrado para o período 1990-2018.

No período 1990-2009, as palavras-chave "turismo cultural" e "cultura" dividem o quarto lugar no ranking das mais citadas, e formam um agrupamento junto com "desenvolvimento local," "patrimônio cultural" e "imagem," esta última com frequência igual a seis, pouco acima do corte mínimo para 1990-2009.

Percebem-se algumas particularidades do agrupamento de turismo cultural, úteis para se analisar sua trajetória. Primeiro, é patente sua baixa capilaridade - há forte polarização exercida por "turismo cultural" e por "cultura." Todas as arestas - internas e com palavras-chave de outros agrupamentos - têm baixo valor; a mais alta liga "turismo cultural" a "patrimônio cultural" (cinco artigos).

É interessante notar também que há uma palavra-chave que não era esperada - "imagem" -, dado que há um agrupamento que traz as palavras-chave "estratégia", "planejamento", "marketing" e "comunicação".

Por mais que ambas as arestas tenham valor igual apenas a três, "cultura" liga-se a "desenvolvimento local" (aresta interna), ao passo que "turismo cultural" liga-se a "desenvolvimento sustentável" (aresta externa). É ilustrativo da trajetória do agrupamento de turismo cultural o fato de as palavras-chave ligadas à temática do desenvolvimento não terem mais nenhuma ligação com ele, no período 1990-2018.

O período 1990-2018 traz o agrupamento de turismo cultural com apenas 139 artigos, muito atrás daqueles centrados em "sustentabilidade" (213) e em "ecoturismo" (208). É possível perceber, por meio da frequência absoluta e da formação dos agrupamentos, que houve a perda de importância relativa do turismo cultural no campo de turismo no Brasil, frente a temáticas ligadas à natureza, ao rural e à sustentabilidade.

As principais palavras-chave continuam a ser "turismo cultural" (108 artigos) e "cultura" (91), em termos de frequência, mas o Gráfico 2 mostra que a última deixou de polarizar o agrupamento com a primeira. Ele centra-se, agora, entre "turismo cultural", de um lado, e "patrimônio" (61) e "patrimônio cultural" (76), do outro. De resto, saíram as palavras-chave "desenvolvimento local" e "imagem", e entraram palavras-chave mais ligadas às ciências sociais - "identidade" (47 artigos), "museus" (22) 
e "memória" (22) -, que são comumente encontradas em estudos acerca do patrimônio cultural, para além do campo de turismo. Dessas três últimas, apenas a primeira tem frequência acima de quatro, no período 1990-2009 - no caso, aparece em nove artigos.

Outro ponto que chama a atenção é o fato de o agrupamento ser o único que não se liga a nenhum dos outros, encontrando-se isolado dentro do campo. Esperava-se que, pelo menos, a palavra-chave "cultura" apresentasse alguma aresta externa, dada sua profundidade conceitual e ampla possibilidade de aplicação. Dado que "turismo cultural" é utilizada, muitas vezes, para delimitar um segmento de mercado, esperava-se também que houvesse alguma aresta externa com os agrupamentos centrados em "destino turístico", "hospitalidade" e/ou "sustentabilidade".

Uma possível explicação para esse isolamento do agrupamento é a predominância de artigos que não se ligam a negócios (non business tourism studies), que representam 89 (64,03\%) dos 139, para utilizar a tipologia proposta por Tribe $(1997,2010)$. Apenas o de ecoturismo tem uma proporção mais alta de artigos que não se ligam a negócios (147 de 208 - 70,67\% do total). Dado que nenhum dos outros quatro têm uma orientação de ciências sociais, e que a maior parte das palavras-chave esteja muito vinculada ao estudo da cultura e do patrimônio cultural, inclusive para além do campo de turismo, é compreensível, ad hoc, que o agrupamento de turismo cultural encontre-se isolado, no período 1990-2018.

\subsection{A produção do agrupamento, por autores, instituições, unidades da federação, grandes regiões e países}

A produção do agrupamento de turismo cultural é relativamente fragmentada, no nível dos autores e instituições. Dos 221 autores únicos, 193 assinam apenas um artigo, sozinhos ou em coautoria. Os dois principais - Karoliny Diniz Carvalho e Pedro de Alcântara Bittencourt César - estão no primeiro centil (1\%) dos autores mais produtivos do campo de turismo no Brasil, ao passo que os demais presentes na Tabela 3 - Silvana Pirillo Ramos, Mario Jorge Pires, Janete Ruiz de Macedo, Roselys Izabel Correa dos Santos e Neus Crous-Costa - produzem relativamente pouco, fora do supracitado agrupamento. Dos sete autores listados na Tabela 3, o que tem a mais baixa porcentagem de seus artigos dentro desse agrupamento é Pedro de Alcântara Bittencourt César, que é também aquele que ocupa a mais alta posição (130) no ranking do campo.

Das 98 instituições, 83 assinam até dois artigos, sozinhas ou em coautoria. Das três primeiras, a Universidade de São Paulo (USP) (nove artigos) e a Universidade do Vale do Itajaí (UNIVALI) (seis) destacam-se como as mais produtivas do campo de turismo no Brasil.

Apesar de ter sido encerrado, a Universidade Estadual de Santa Cruz (UESC) contou já com o Programa de Pós-Graduação em Cultura e Turismo, bem como edita a CULTUR, periódico que mais tem publicado artigos desse agrupamento, como mostra a Tabela 7 . Se a instituição assina apenas $2,11 \%$ dos 3.887 artigos do campo, essa proporção aumenta em torno de cinco vezes para o agrupamento de turismo cultural, sendo quase igual à USP e UNIVALI somadas. Não por acaso, dentre as quatro instituições da Tabela 4, a UESC é a que tem a mais alta porcentagem de seus artigos dentro desse agrupamento, em proporção muito mais alta do que as demais.

Em linhas gerais, a importância da UESC é a principal explicação para o aumento da importância da Região Nordeste no agrupamento, em relação ao campo como um todo. Maranhão e Alagoas mais do que dobram sua participação no agrupamento, em relação ao campo, mas ambos partem de baixas porcentagens. E, como mostra a Tabela 7, o periódico com mais alta sobre representação é editado pela Universidade Federal de Alagoas (UFAL) - a RITUR.

Por fim, no caso dos países, o agrupamento de turismo cultural é aquele no qual o Brasil tem a mais baixa porcentagem. Todos os países que assinam, pelo menos, um artigo têm o português ou o espanhol como idioma oficial, com exceção de França. Dos países estrangeiros, os dois mais importantes guardam estreitas relações culturais com o Brasil. Inclusive, a RITUR é fruto de convênio entre a UFAL e a Universitat de Girona, por meio do apoio da Agencia Española de Cooperación Internacional para el Desarrollo.

É interessante notar que as relativamente altas porcentagens de Espanha e Portugal não se devem a nenhuma instituição em particular, pois sua produção é fragmentada entre várias universidades.

\subsection{A estrutura intelectual do agrupamento, por meio das referências bibliográficas de seus artigos}

Como é facilmente perceptível, por meio da Tabela 2, dentre os cinco agrupamentos, o de turismo cultural é o que apresenta, em suas referências bibliográficas, a mais baixa proporção de artigos de periódico (campo de turismo e outros) e de monografias, assim como a mais alta porcentagem de livros e capítulos de livro. 
Isso é reflexo, provavelmente, de dois pontos, a saber: a) a orientação de ciências sociais, a julgar por suas palavras-chave e isolamento (período 1990-2018): as ciências sociais dependem mais de livros para a construção e transmissão de conhecimento, em relação a outras grandes áreas de conhecimento; e b) a eventual dependência ainda de textos didáticos e introdutórios: a coleta de dados, para o campo de turismo como um todo, revelou que os livros didáticos são ainda muito presentes nas referências bibliográficas, ao contrário, por exemplo, de o que ocorre nos principais periódicos internacionais de turismo (Benckendorff \& Zehrer, 2013; Racherla \& Hu, 2010). Isso demonstra um estágio de ainda amadurecimento do agrupamento, no qual esse fenômeno parece ser mais acentuado.

Que se somem, a esses dois pontos, as mais baixas média e mediana de referências bibliográficas por artigo, dentre os cinco agrupamentos, para se ter algo que não ocorre em nenhum outro, além do de turismo cultural, a saber: praticamente, não há uma rede de periódicos formada - eles não conseguem delimitar uma clara estrutura intelectual.

Como mostram a Tabela 8 e o Gráfico 4, dos 14 autores mais produtivos, três são organizações ou governos, ao passo que dois indivíduos - Mario Carlos Beni e Reinaldo Dias - são autores muito citados no campo como um todo, cuja influência vai muito além desse agrupamento. Dos nove autores restantes, o único que tem uma postura marcadamente orientada ao mercado é Greg Richards; todos os demais transitam entre as várias ciências, disciplinas e campos ligados às ciências sociais.

O Gráfico 4 ressalta o domínio de Margarita Barretto na estrutura intelectual. Não apenas é a autora (indivíduo) mais citada, ela ocupa também papel central no grafo de coautorias - liga-se, por meio de cocitações, com nove outros autores. Apenas Mario Carlos Beni (cinco) e Stuart Hall (quatro) têm quatro ou mais arestas. Chama a atenção o fato de John Urry ligar-se apenas a Mario Carlos Beni, mesmo The tourist gaze (Urry, 2002) tendo se tornado um dos textos centrais na estrutura intelectual dos principais periódicos internacionais de turismo, como mostram Benckendorff e Zehrer (2013).

Dois pontos chamam também a atenção. Primeiro, não há uma aresta que ligue John Urry e Stuart Hall, por mais que ambos sejam muito ligados à discussão da pós-modernidade e turismo. Segundo, por mais que sejam autores relativamente pouco citados, há uma aresta (seis artigos) entre Jacques Le Goff e Pierre Nora, o que indica um subgrupo de artigos que trabalham com história.

A análise das obras mais citadas e cocitadas, por meio da Tabela 9 e do Gráfico 5, permite ir além de o que foi feito com base nos autores. Dos 10 textos, nove são livros - reforça a ainda baixa importância dos artigos de periódico no agrupamento de turismo cultural. Há um texto técnico - Turismo cultural: orientações básicas (Brasil, 2010). Há um contraste curioso, a saber: os cinco livros de autores brasileiros ou radicados no Brasil são didáticos ou introdutórios, ao passo que os quatro volumes de autores internacionais abordam determinado tema ou assunto em profundidade. Há um volume que é o texto mais presente nas referências bibliográficas do campo de turismo no Brasil, e aparece em destaque em todos os agrupamentos - Análise estrutural do turismo (Beni, 1998).

Mais uma vez, reforça-se o domínio de Margarita Barretto no agrupamento. O volume Turismo e legado cultural (Barretto, 2003) ocupa o centro do grafo de cocitações. Há apenas uma aresta que não inclui esse livro.

Reforça-se também a noção, que aparece já nas palavras-chave, do estreito vínculo entre turismo cultural e patrimônio cultural. Por outro lado, é notável a ausência de textos sobre a cultura, por mais que História e memória (Goff, 2013) ligue-se a Turismo e legado cultural (Barretto, 2003).

Há apenas quatro periódicos que são utilizados, nas referências bibliográficas, em, pelo menos, 13 artigos. Temos a segunda revista mais antiga do campo de turismo no Brasil (RTVA) e um dos principais periódicos internacionais de turismo (Annals of Tourism Research). Os dois outros têm afinidade específica ao agrupamento. A Pasos. Revista de Turismo y Patrimonio Cultural tem uma temática muito próxima a do agrupamento, ao passo que a Horizontes Antropológicos é uma das principais revistas brasileiras de antropologia. Dada a lista de principais autores e obras, era esperado que a antropologia fizesse parte importante da estrutura intelectual do agrupamento.

As ausências mais notadas são dois periódicos nacionais, a TA e a CULTUR. A primeira é o periódico pioneiro do campo de turismo no Brasil; a segunda é um periódico que traz, já em seu título, a relação entre turismo e cultura.

\subsection{A distribuição dos artigos do agrupamento de turismo cultural entre os 16 periódicos do campo de turismo no Brasil}

Dos 16 periódicos, apenas dois não publicaram nenhum artigo no agrupamento de turismo cultural. A RLAT é relativamente nova, com apenas 48 artigos publicados. Dos cinco agrupamentos, há artigos 
dessa revista científica apenas no centrado em sustentabilidade. Já a AT tem orientação aplicada, e conta com 80 artigos publicados. Parece ser sintomático o agrupamento de turismo cultural não ter nenhum artigo publicado na única revista científica de orientação marcadamente aplicada do campo de turismo no Brasil.

Os dois periódicos com mais alta sobre representação são ambos da Região Nordeste, cujas instituições responsáveis - UFAL (RITUR) e UESC (CULTUR) - são também sobre representadas no agrupamento. A CULTUR traz a relação entre cultura e turismo em seu próprio nome.

É algo preocupante verificar que, dos cinco agrupamentos, apenas o de turismo cultural é sub representado, simultaneamente, naqueles que são considerados os quatro principais periódicos do campo de turismo no Brasil - CVT, RBPT, RTVA e TA. É difícil afirmar o porquê de isso acontecer. Fazer uma ligação com algumas características da estrutura intelectual do agrupamento, notadamente a baixa representatividade das revistas científicas e a centralidade de textos didáticos e introdutórios, pode ser um caminho promissor. De todo modo, seria necessário ter acesso aos artigos rejeitados pelas supracitadas revistas científicas, preferencialmente com seus pareceres, para elaborar uma análise mais apurada.

\subsection{O impacto do agrupamento de turismo cultural}

De modo geral, os dados relativos ao impacto do agrupamento não diferem muito dos encontrados para o campo de turismo como um todo. Na média de citações reais por artigo, o de turismo cultural fica acima apenas do centrado em hospitalidade, mas apenas um pouco abaixo do verificado para o campo - 2,63 frente a 2,8 .

Dentro do agrupamento de turismo cultural, não há diferença significativa entre os artigos classificados como estudos ligados a negócios turísticos $(2,62)$ e aqueles classificados como estudos não ligados a negócios turísticos $(2,64)$.

No conjunto dos 70 artigos com mais citações ${ }^{2}$, há apenas dois do agrupamento de turismo cultural. Ambos consistem em estudos introdutórios ao tema, com particular preocupação em explicitar conceitos, e indicar e comentar as referências-chave da área. Köhler e Durand (2007) têm uma clara orientação de gestão e marketing, tratando a cultura e o patrimônio cultural como base para a criação de produtos turístico-culturais mercadejáveis. Já Batista (2005) traz uma útil reflexão sobre a importância da memória e identidade para o turismo cultural. Curiosamente, na linha de "santo de casa não faz milagre", ambos são pouco importantes na estrutura intelectual do agrupamento. O primeiro é citado por apenas três artigos, ao passo que o segundo não é por rigorosamente nenhum.

\section{Considerações finais}

Dentre os cinco existentes no período 1990-2018, o agrupamento de turismo cultural é apenas o quarto em número de artigos (139 de 3.887 - 3,28\% do total). Além disso, ele apresentou crescimento, ao longo dos anos 2010, mas em escala não tão alta quanto à verificada nos agrupamentos de "sustentabilidade" e de "ecoturismo." Parece que o turismo cultural está firmemente estabelecido no campo de turismo no Brasil, mas não tem a mesma força que o ecoturismo nem sequer o turismo rural, tampouco as discussões acerca da sustentabilidade, particularmente atreladas à questão do desenvolvimento.

De todo modo, o agrupamento de turismo cultural é claramente delimitado, e congrega um conjunto de palavras-chave "esperadas", que orbitam em torno do turismo cultural, da cultura e do patrimônio.

Chama particular atenção a orientação de ciências sociais presente no agrupamento. Há relativamente poucos artigos preocupados com o turismo cultural como um segmento de mercado, por meio da gestão e/ou do marketing. Isso se reflete, muito claramente, em sua estrutura intelectual. Com exceção de Greg Richards (ranking de autores), as tabelas 8, 9 e 10 e os gráficos 4 e 5 mostram que a estrutura intelectual é marcada, majoritariamente, por autores, obras e periódicos mais ligados às ciências sociais. Por exemplo, não há nenhuma revista científica de marketing nem sequer de administração, que se destaque na estrutura intelectual do agrupamento.

Parece tratar-se também de um agrupamento ainda em estágio de maturação, em relação aos outros quatro e mesmo ao campo de turismo no Brasil. Há mais baixo uso de referências bibliográficas por artigo, na média e na mediana; a porcentagem de artigos de periódico (de turismo e outros) é muito baixa. De todos os agrupamentos, o de turismo cultural é o único que não forma uma rede de cocitações de revistas científicas minimamente estruturada. Trata-se de uma consequência da grande importância dos livros nas referências bibliográficas; no topo do ranking das obras, destacam-se, em número, os livros de caráter didático e introdutório. 
É interessante notar o destaque de Margarita Barretto e seu volume Turismo e legado cultural (Barretto, 2003), tanto nos rankings quanto nas redes de autores e obras. Contudo, por meio da leitura transversal dos 139 artigos, ela parece exercer um papel similar ao de Mario Carlos Beni para o campo como um todo, mas apenas para o agrupamento de turismo cultural. As citações feitas à supracitada autora servem para sustentar afirmações de cunho introdutório ou geral, a exemplo do crescimento do turismo cultural, nos últimos anos.

$\mathrm{Na}$ autoria, destaca-se a sobre representação da Região Nordeste do Brasil no agrupamento, devido, principalmente, à UESC. Há paralelo nessa sobre representação tomando-se os 16 periódicos brasileiros de turismo, com os casos da RITUR e da CULTUR, vistos anteriormente. Ao lado do composto sexo, sol, mar e praia, a cultura e o patrimônio cultural sempre foram usados como atrativos turísticos, no caso da Região Nordeste, inclusive por vários programas federais de grande porte de turismo e patrimônio, a saber: a) Programa de Reconstrução das Cidades Históricas do Nordeste, com sua utilização para fins turísticos; b) Programa MONUMENTA; c) Programas Regionais de Desenvolvimento do Turismo (PRODETUR) - várias edições; e d) Programa de Aceleração do Crescimento - Cidades Históricas. Contudo, é importante fazer a seguinte advertência: a sobre representação deve-se, essencialmente, à UESC. Seu Programa de Pós-Graduação em Cultura e Turismo foi encerrado, há cerca de 10 anos, mas a sobre representação da instituição continuou firme, ao longo dos anos 2010.

Para fechar o presente artigo, cumpre destacar os últimos três pontos. Primeiro, os resultados mostram que o agrupamento tem várias lacunas, em relação ao que é verificado nos periódicos internacionais de turismo. A questão da autenticidade aparece, de forma pronunciada, em poucos artigos. Para nenhum dos três períodos em análise, a palavra-chave "autenticidade" passa pelo ponto de corte. É provável que esse é o motivo principal de Erik Cohen não aparecer entre os principais autores. Com exceção de Greg Richards, há nítida ausência de autores e obras que trabalhem o turismo cultural, sob uma perspectiva de negócios, tanto na esfera privada quanto no setor público.

Segundo, é curioso que a estrutura intelectual do agrupamento não traga, entre seus principais autores, nenhum dos indivíduos listados na Tabela 3, nem sequer os responsáveis pelos dois artigos mais citados - André Fontan Köhler, José Carlos Garcia Durand e Cláudio Magalhães Batista. Outra ausência notada é Mário Jorge Pires, cujo livro Lazer e turismo cultural (Pires, 2001) é muito citado na literatura ${ }^{3}$. O autor é considerado como um dos pioneiros do estudo do turismo cultural no Brasil.

A principal limitação do presente artigo é ter se baseado, para a criação e delimitação dos agrupamentos, nas palavras-chave dos 3.887 artigos do campo de turismo no Brasil. Dado que os próprios autores escolhem suas palavras-chave, por mais que elas possam ser mudadas, conforme sugestões emitidas pelos pareceristas, não há nenhuma garantia de que elas sempre retratem, fidedignamente, o conteúdo do artigo em questão. Além disso, o Tesauro Brasileiro de Turismo é de publicação recente, e sua aplicação obrigatória não atinge todos os periódicos brasileiros de turismo. Outra limitação reside no próprio objeto de estudo; a produção científica em turismo no Brasil vai muito além dos 3.887 artigos publicados nos 16 periódicos selecionados.

Será útil comparar os resultados da presente pesquisa com os agrupamentos criados e delimitados pelo conjunto de referências bibliográficas dos 3.887 artigos - autores, obras e revistas científicas. Trata-se de um caminho promissor para nossas pesquisas futuras.

\section{Bibliografía}

Batista, C. M. (2005). Memória e identidade: aspectos relevantes para o desenvolvimento do turismo cultural. Caderno Virtual de Turismo, 5(3), 27-33.

Barretto, M. (2003). Turismo e legado cultural. Papirus.

Benckendorff, P. (2009). Themes and trends in Australian and New Zealand tourism research: a social network analysis of citations in two leading journals (1994-2007). Journal of Hospitality and Tourism Management, 16(1), 1-15. https://doi.org/10.1375/jhtm.16.1.1

Benckendorff, P. \& Zehrer, A. (2013). A network analysis of tourism research. Annals of Tourism Research, 43, 121-149. https://doi.org/10.1016/j.annals.2013.04.005

Beni, M. C. (1998). Análise estrutural do turismo. Senac.

Bertero, C. O., Caldas, M. P. \& Wood Jr., T. (1999). Produção científica em administração de empresas: provocações, insinuações e contribuições para um debate local. Revista de Administração Contemporânea, 3(1), 147-178. https://doi.org/10.1590/S1415-65551999000100009

Biglan, A. (1973). The characteristics of subject matter in different academic areas. Journal of Applied Psychology, 57(3), 195-203. https://doi.org/10.1037/h0034701 
Brasil. Ministério do Turismo. (2010). Turismo cultural: orientações básicas. http://www.turismo.gov. br/sites/default/turismo/o_ministerio/publicacoes/downloads_publicacoes/Turismo_Cultural_Versxo_Final_IMPRESSxO_.pdf

Choay, F. (2006). A alegoria do patrimônio. 3. ed. Estação Liberdade : UNESP.

Dias, R. (2006). Turismo e patrimônio cultural: recursos que acompanham o crescimento das cidades. Saraiva.

Funari, P. P. \& Pinsky, J. (Orgs.) (2014). Turismo e patrimônio cultural. Contexto.

Goff, J. (2013). História e memória. Editora da UNICAMP.

Grauwin, S. \& Jensen, P. (2011). Mapping scientific institutions. Scientometrics, 89, 943. https://doi. org/10.1007/s11192-011-0482-y

Hall, S. (2004). A identidade cultural na pós-modernidade. Lamparina.

Hall, C. M. (2011). Publish and perish? Bibliometric analysis, journal ranking and the assessment of research quality in tourism. Tourism Management, 32(1), 16-27. https://doi.org/10.1016/j. tourman.2010.07.001

Jamal, T., Smith, B. \& Watson, E. (2008). Ranking, rating and scoring of tourism journals: interdisciplinary challenges and innovations. Tourism Management, 29(1), 66-78. https://doi.org/10.1016/j. tourman.2007.04.001

Kessler, M. M. (1963). Bibliographic coupling between scientific papers. American Documentation, 24, 123-131. https://doi.org/10.1002/asi.5090140103

Kirilenko, A. P. \& Stepchenkova, S. (2018). Tourism research from its inception to present day: subject area, geography, and gender distributions. PLos ONE, 13(11), e0206820. https://doi.org/10.1371/ journal.pone.0206820

Koc, E. \& Boz, H. (2014). Triangulation in tourism research: a bibliometric study of top three tourism journals. Tourism Management Perspectives, 12, 9-14. https://doi.org/10.1016/j.tmp.2014.06.003

Köhler, A.F. \& Durand, J. C. G. (2007). Turismo cultural: conceituação, fontes de crescimento e tendências. Revista Turismo - Visão e Ação, 9(2), 185-198. https://doi.org/10.14210/rtva.v9n2.p185-198

Köhler, A. F. \& Digiampietri, L. A. (2021). Estudos de hospitalidade: análise bibliométrica e de redes sociais do campo de turismo no Brasil, 1990-2018. Revista Hospitalidade, 18(1), 104-135.

Koseoglu, M. A., Rahimi, R., Okumus, F. \& Liu, J. (2016). Bibliometric studies in tourism. Annals of tourism research, 61, 180-198. https://doi.org/10.1016/j.annals.2016.10.006

Law, R. \& Veen, R. (2008). The popularity of prestigious hospitality journals: a Google Scholar approach. International Journal of Contemporary Hospitality Management, 20(2), 113-125. https:// doi.org/10.1108/09596110810852113

Laws, E. \& Scott, N. (2015). Tourism research: building from other disciplines. Tourism Recreation Research, 40(1), 48-58. https://doi.org/10.1080/02508281.2015.1005926

Leta, J. \& Lewison, G. (2003). The contribution of women in Brazilian science: a case study in astronomy, immunology and oceanography. Scientometrics, 57, 339-353. https://doi.org/10.1023/A:1025000600840

McKercher, B. (2005). A case for ranking tourism journals. Tourism Management, 26(5), 649-651. https://doi.org/10.1016/j.tourman.2004.04.003

McKercher, B. (2008). A citation analysis of tourism scholars. Tourism Management, 29(6), 1.226-1.232. https://doi.org/10.1016/j.tourman.2008.03.003

Meneses, J. N. C. (2013). História \& turismo cultural. Autêntica.

Mulet-Forteza, C., Genovart-Balaguer, J., Mauleon-Mendez, E. \& Merigó, J. M. (2019). A bibliometric research in the tourism, leisure and hospitality fields. Journal of Business Research, 101, 819-827. https://doi.org/10.1016/j.jbusres.2018.12.002

Otte, E. \& Rousseau, R. (2002). Social network analysis: a powerful strategy, also for the information sciences. Journal of Information Science, 28(6), 441-453. https://doi.org/10.1177/016555150202800601

Pires. M. J. (2001). Lazer e turismo cultural. Manole.

Racherla, P. \& Hu, C. (2010). A social network perspective of tourism research collaborations. Annals of Tourism Research, 37(4), 1.012-1.034. https://doi.org/10.1016/j.annals.2010.03.008

Tribe, J. (1997). The indiscipline of tourism. Annals of Tourism Research, 24(3), 638-657. https://doi. org/10.1016/S0160-7383(97)00020-0

Tribe, J. (2010). Tribes, territories and networks in the tourism academy. Annals of Tourism Research, 37(1), 7-33. https://doi.org/10.1016/j.annals.2009.05.001

Strandberg, C., Nath, A., Hemmatdar, H. \& Jahwash, M. (2018). Tourism research in the new millennium: a bibliometric review of literature in Tourism and Hospitality Research. Tourism and Hospitality Research, 18(3), 269-285. https://doi.org/10.1177/1467358416642010 
Urry, J. (2002). The tourist gaze. Second edition. Sage.

Ye, Q., Li, T. \& Law, R. (2013). A coauthorship network analysis of tourism and hospitality research collaboration. Journal of Hospitality \& Tourism Research, 37(1), 51-76. https://doi. org/10.1177/1096348011425500

Xiao, H. \& Smith, S. L. J. (2006). The making of tourism research: Insights from a Social Sciences Journal. Annals of Tourism Research, 33(2), 490-507. https://doi.org/10.1016/j.annals.2006.01.004

\section{Notas}

1 O Qualis Periódicos é o sistema brasileiro de avaliação de periódicos, mantido pela Coordenação de Aperfeiçoamento de Pessoal de Nível Superior. Os periódicos são classificados pelas áreas de avaliação, nos quais pesquisadores vinculados aos programas de pós-graduação stricto sensu brasileiros publicaram seus trabalhos. Atualmente, há 49 áreas de avaliação. Cada uma classifica os periódicos considerados relevantes para a área em sete categorias (A1, A2, B1, B2, B3, B4 e B5), sendo A1 a classificação mais importante e B5 a menos.

2 Para a delimitação desse conjunto, foi selecionado o primeiro centil (1\%) dos artigos com mais impacto, para todas as citações reais e para as citações reais, de acordo com cada tipo de quem cita (artigo de periódico, livro, monografia [dissertação de mestrado e tese de doutorado] etc.). Batista (2005) está no primeiro centil das citações reais totais, ao passo que Köhler e Durand (2007) entram na lista, por meio das citações reais feitas por artigos de periódico.

3 Em 08 de agosto de 2020, Pires (2001) tinha 184 citações nominais no Google Acadêmico. Para efeito de comparação, Barretto (2003) apresentava 405 citações nominais, por meio também do Google Acadêmico e na mesma data. 